losers-it focuses on exchange and builds on the respective strengths of institutions and countries. Importantly, it recognizes that benefits will differ among partners and countries.

In our highly interdependent world, higher education facilitates the cross-border flow and the exchange of people, knowledge, values, innovation, economy, technology, and culture. But why is it framed in a "power paradigm" like soft power? Are the values of self-interest, competition, or dominance going to effectively address issues of worldwide epidemics, terrorism, failed states, the bottom billion in poverty and climate change? The answer is no. This is based on the reality that solutions to worldwide challenges cannot be achieved by one country alone.

An alternative to the power paradigm is the framework of diplomacy. Diplomacy, interpreted as the management of international relations, focuses on negotiation, mediation, collaboration, compromise, and facilitation. These are different tactics and concepts than those attached to power dominance, authority, command, and control. Is knowledge diplomacy more appropriate to frame the role of higher education in international relations, than the soft power paradigm?

Knowledge is a cornerstone of today's interconnected world. The evolution from the new information and communication technologies of cyberspace, to the big data of infospace, to the knowledge processing of knowspace brings new opportunities and complexities to international higher education. However, there is no denying that knowledge can also lead to power imbalances within and among countries. This reality is exacerbated when higher education and knowledge are seen as tools of soft power. The alternative of using collaboration and mediation strategies of diplomacy requires serious consideration.

International higher education has the opportunity of moving beyond its preoccupation, with the knowledge economy, and takes a proactive role to ensure that knowledge is effectively used to address worldwide challenges and inequalities, by recognizing the mutuality of interests and benefits. Is higher education ready to take a lead in promoting the notion of knowledge diplomacy and not remain stuck, in the soft power frame of self-interest and dominance?

\section{Sustaining Quality and Massification: Is It Possible?}

\section{Marcelo Knobel}

Marcelo Knobel is professor at the Instituto de Física Gleb Wataghin, Universidade Estadual de Campinas (Unicamp), Campinas, SP, Brazil. knobel@ifi.unicamp.br.

Higher education has experienced rapid expanding enrollment worldwide for the last 40 years. This growth will probably continue for the next 20 years, with predictions of 400 million students in 2030 (compared with 100 million in 2000). Is it possible to make this massification more equitable, while insuring minimum standards of quality?

Different countries and regions of the world are at different stages of higher education development. Gross enrollment ratios depend on a nation's degree of economic development, social environment, history, and policy priorities. While many countries still struggle to guarantee access to higher education for a predominantly young population, other countries face the challenges of an aging population and/or decrease of government support.

In the case of Latin America, for example, all countries still struggle with strong-social inequality. Increasing participation and degree attainment at the tertiary level are not only fundamental for forthcoming development but also key to social mobility, particularly for underrepresented groups-disadvantaged socioeconomic sectors, Afrodescendants, and indigenous people. There has been progress in the region in terms of student enrollments, growing from I.6 million students in I970 to 20 million in 2009 . The gross enrollment ratio is around 30 percent in the region, indicating that there is yet room to further growth. In addition, growth remains uneven, mainly favoring certain segments of the population.

The funding sources of higher education-governments, students, and families, or for-profit ventures-has a strong influence on the quality provided. For example, there are many concerns regarding higher education quality, when it is focused on financial return. Unfortunately, the appetite for short-term financial gain often distracts attention from long-term planning, leading to a lack of investment in infrastructure, faculty qualifications, and program stability, and thus jeopardizing quality. Additionally, although the for-profit sector has had an important "demandabsorbing" role, these institutions are often given too much latitude by national authorities for the quality of services they provide.

Finally, massification inevitably presents the challenge of teaching a more diverse group, increasing the share of students with substantial gaps in their previous education. 
Higher education institutions must develop specific programs to guarantee not only the access but the success of every student, reducing the failure and dropouts rates. This must be done without compromises to the quality of the final degree awarded.

Countries must implement policies that provide access to education for socially and economically disadvantaged sectors; that establish and insure robust-quality assurance and monitoring processes; and that create a framework to encourage institutional diversity and innovative, equitable funding mechanisms. It is difficult to imagine a comprehensive solution, but each different country must try to find a good balance between funding, access, and quality in this complicated wrangle. A long-term, sustainable solution for the growth of the higher education sector is mandatory for the economic and social stability of any nation.

\section{Do Not Fall For It}

\section{DANiEL C. LeVy}

Daniel C. Levy is a State University of New York Distinguished Professor, University at Albany, New York. E-mail: dlevy@albany.edu.

Zaniness is required to try to answer a question about higher education's greatest imminent need, so I consult and paraphrase comedian Groucho Marx: "A four-year-old child could answer this question. Run out and find me a fouryear-old child, I can't make head or tail out of it." Or maybe I could escape by discrediting the question, or at least declaring it unanswerable? But those might be ungracious responses to a gracious invitation. Most of us are interested in the answers given by colleagues who have spent their professional lives studying higher education.

Does the question's reference, to what higher education needs to deal with, concern higher education's self-interests or serving others? Only the likes of university presidents and magical solution policypushers can present these interests as nearly identical. Also, how could any answer make sense across the hugely varied realities of societies, political systems, economies, levels of development, interests, and values on the one hand and of higher education structures and functions on the other? However, many colleagues may answer with research universities in mind. I could not be comfortable with a singular substantive and prescriptive action answer for all of higher education.

Higher education's biggest need is to steer clear of, or significantly modify, seductively attractive idealistic visions or policy proposals. Obviously, we want to resist insidious or meritless proposals; when they are imposed on us, we go kicking and screaming. But even the visions and proposals, which have alluring merit and should be seriously considered, come our way with vastly exaggerated claims of likely benefits. In some places, between no and inadequate allowance for the myriad costs, those that can be anticipated and those that cannot be. Compose your own list from yesteryear and today. Unfortunately, yesteryear's inflated claims remain — what increased funding of higher education will do for development, how rapid and diversified expansion of access will bring equity and productive benefits, how government money will achieve mutually held progressive aims. These claims are now joined by grand visions of how to build world-class universities and what will be reaped from quality-assurance agencies, benchmarks, massive open line courses, or increased market competition.

This is not an ivory-tower rant against outsiders. My answer holds for bold visions and proposals springing from inside academia, including from higher education studies experts. I would trust more to invisible hands-in which I have only limited trust- than to prescriptions from gurus, let alone from wise-guys outside academia, to determine what higher education needs to do.

\section{Sustaining Resources}

\section{SimON MARGinson}

Simon Marginson is professor at the Institute of Education, University College London, UK. E-mail: s.marginson@ioe.ac.uk.

The key challenge facing higher education in the next decade is mundane but central: sustaining resources. Behind that lies a deeper historic problem, relations between higher education and the nation state.

Worldwide modern higher education systems are the product of the nation-building strategies of governments. Tuition arrangements vary markedly, but overall, up till now, government has funded most of the infrastructure and most of the operating costs of better institutions in one way or another. Governments subsidize the growth of access to newly participating families and foster opportunities for social mobility through higher education. Government is also essential to funding research, a public good subject to market failure. However, matters are now changing in many countries. Research still depends on public funding, and governments want to concentrate resources there to maximize national competitiveness. But teaching can be either public or private good. 